\title{
Anthropology as a Natural Science Clifford Geertz's Extrinsic Theory of the Mind
}

\author{
Alphonso Lingis \\ The Pennsylvania State University, State College, USA \\ Email: allingis@hotmail.com \\ Received 27 January 2014; revised 27 February 2014; accepted 7 March 2014 \\ Copyright (C) 2014 by author and Scientific Research Publishing Inc. \\ This work is licensed under the Creative Commons Attribution International License (CC BY). \\ http://creativecommons.org/licenses/by/4.0/

c) (i) Open Access

\begin{abstract}
Clifford Geertz set forth interpretative anthropology as a natural science, based on "the extrinsic theory of the mind". Observation of the use of words and cultural symbols will determine theory meaning. Symbols are models or templates, and enter into the constitution of every perceived object or event we recognize or identify. We do not perceive what others perceive, but what they perceive "with", "by means of", or "through". But the objects and events we or others perceive are already and from the first symbolic. Thoughts and emotions are articulated, generated and regenerated by words and other symbolic objects. Without, or before, words and symbols, there is only general, diffuse, ongoing flow of bodily sensation. This essay criticizes these theses in the light of the philosophy of mind and the phenomenology of perception.
\end{abstract}

\section{Keywords}

Geertz; Interpretative Anthropology; Symbol; Meaning; Perception

\section{Anthropology as a Science}

The founders of modern anthropology enjoined methods of rigorous, systematic, controlled, and verified observation, mathematized data, and value-free concepts that would constitute anthropology as a science (Tylor, 1881; Malinowski, 2001; Radcliffe-Brown, 1957; Boas, 1974). Today anthropology comprises archaeology and biological, forensic, and evolutionary anthropology, which figure as natural sciences (Hebb, 1949; Nikityuk, 1978). Linguistic anthropology, social anthropology, and the structuralist anthropology inaugurated by Claude LéviStrauss are constructed as objective empirical researches (Fettes, 2000; Milroy \& Gordon, 2003; Lévi-Strauss, 1983). The anthropological study of myths and religions breaks with literary and theological studies by suspending belief and elaborating comparative studies. Cultural anthropologists have often understood this study as akin to sociology, history, and psychology, and have drawn concepts and explanatory paradigms from those dis- 
ciplines.

Clifford Geertz identified symbols to be the fundamental datum of cultural anthropology, and conceived cultural anthropology as the interpretation of symbols. However, he argued that the meaning of the symbols was subject to empirical observation, and that interpretative anthropology will be a natural science like any other. Critics questioned the verifiability of the ethnographer's interpretations (Shankman, 1984, Scholte, 1986; Kapferer, 1988; Carrithers, 1988, 1990; Hobart, 1990; Gottowik, 1997; Kuper, 1999; Descombes, 2002; Yoshida, 2009). Other critics, emphasizing the dialogical nature of anthropological research-the political and psychological relations the informant has with other members of his community and with the researcher and that shape what the informant tells the researcher, and the political and psychological relations the researcher has with the informant and with his or her community - have objected that ethnographic data are not simply objective data, like data about agricultural and housing practices the ethnographer can assemble (Tambiah, 1985; Biersack, 1989; Fabian, 1991; Borofsky, 1993; Rosaldo, 1993). The uses of symbols are not simply empirical observed, but interpreted within the dialogic relationship the researcher has with his or her informants. This has led to recasting anthropological texts such that they incorporate autobiographic reflections on the research and the researcher - which implicate new questions about the scientific character of those texts (Clifford \& Marcus, 1986; Tyler, 1987; Marcus, 1998; Hymes, 1999; Crapanzano 2003).

Geertz in his practice did not restrict himself to the natural science program he formulated. While he consistently objected to positivist conceptions of anthropological research, inhis appraisal of the works of ethnographers he noted with appreciation different conceptions of anthropological research and writing (Handler, 1991; Geertz, 2000, 2002, 2002). It will be a most instructive task to map out all the varied conceptions of ethnographic fieldwork and writing that show through across these writings.

In this study, however, we shall return to Geertz's original statement and bring out the epistemology it contains. What behaviorist theory of mind did Geertz elaborate, and just how did he understand and picture symbols? Did he really show how these could be empirically observed? We shall show shortcomings in his conception of symbols and in his conception of how symbols are perceived. We shall argue that the observation of the use of symbols is not equivalent to understanding their meaning. We shall show limits to the cultural construction of emotions. We shall argue that individuals elaborate "private myths.” We shall analyze more closely how symbols are understood by a multiplicity of individuals in a culture.

\section{The Observation of Thought}

Anthropology, Clifford Geertz notes, could hardly report on human behaviors and societies without recording “desire, zest, truth, love, knowledge, values"1. But Geertz is committed (Geertz, 1973: p. 362) to anthropology as a natural science like any other. These "mental” phenomena presented a theoretical problem as long as they were taken to be phenomena known only by introspection, being phenomena with but one witness. Ascribing them to others could then only be a projection, based on a hypothetical analogy with one's own mind.

Things are different if insight, understanding, conceptual thinking, imagination, feeling, reflection, fantasy, etc., are conceived as skills, propensities, capacities, tendencies, or habits (Geertz, 1973: p. 58). Such terms have the same epistemological status as force, gravitation, or causation in the hard sciences. The capacity for reasoning is the disposition to produce logically structured sequences of propositions, and the existence of the capacity is inferred from logically structured sequences of propositions that are observably produced.

We can object that the production of such a sequence of propositions is not of itself reasoning; reasoning involves insight that the conclusion logically follows from the premises, and that insight is an event in a conscious individual. Once one has seen, and remembers that one has seen, that the conclusion follows, one reproduces the formulation without reproducing the insight. Once one has constructed the proof for the hypotenuse of a right triangle and "seen" its validity, one can use the conclusion as a premise as in a calculus without reawakening the insight.

The scientist would have two methods of distinguishing reasoning from unthinking production of arguments, distinguishing real affection or real regret from the cold production of words and gestures. Observing the sequence of discourse, or of apparently impassioned words and gestures, she detects sequences that are not logically valid or words and gestures that are atypical of states of anger or regret. And she can ask the other if he in fact sees the logic of his statements or feels real anger or regret. Observing the course of what the other then

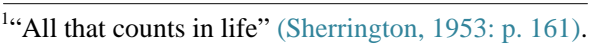


says she may detect signs of insincerity or deception in what the other says.

\section{Symbols as Models}

The central thesis that would enable anthropology to become an empirical natural science is the thesis that "thought consists of the construction and manipulation of symbol systems, which are employed as models of

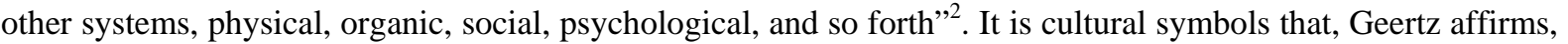
first articulate, generate and regenerates thought. To think is to identify things and relate them with words and other cultural symbols.

Symbols are external to the thinker; they are words and also images, markings, gestures, rituals, graven idols, water holes, tools (Geertz, 1973: p. 362). In addition to perceptible characteristics, symbols have meaning. Geertz invokes Max Weber's (1963) declaration that the imposition of meaning on life is the major end and primary condition of human existence. "Symbol systems, man-created, shared, conventional, ordered, and indeed learned, provide human beings with a meaningful framework for orienting themselves to one another, to the world around them, and to themselves" (Geertz, 1973: p. 250).

Indeed, Geertz (1973: pp. 61-69) argues that the body distinctive of the human speciesis a cultural artifact. The evolution of tool-making, hunting, and a system of communication - these elementary symbolic systemsin Australopithecus, three or four million years ago provoked the development of the more erect stature, reduced dentition, more thumb-dominated hand, and expansion of the brain that came to characterize Homo sapiens sapiens who appeared two hundred thousand years ago.

The meaning of symbols is the way they refer to other systems-physical, organic, social, psychological, etc. "The meanings that symbols, the material vehicles of thought embody are often elusive, vague, fluctuating, and convoluted, but," Geertz affirms that "they are, in principle, as capable of being discovered through systematic empirical investigation as the atomic weight of hydrogen or the function of the adrenal glands" (Geertz, 1973: pp. 362-363). Since we can see or hear words as just visual or sound patterns and water holes as just water holes, the perception of symbols involves a distinctive structure in the perceiving act that philosophers of mind have designated symbolic intentionality: taking the perceived object to refer to something else. Geertz speaks of it as "matching" the symbol with the perceived object or event ${ }^{3}$. We see a small wooden cross and match it up with the cross on which Jesus was crucified.

The concept of meaning, central to cultural hermeneutics, is, truth to tell, not very clear. It is not simply intellectual, conceptual meaning, grasped in conscious acts. Geertz reports (Geertz, 1973: pp. 134-135) that when the Javanese speak of their sense of rituals and ceremonies they speak of rasa, a term uniting taste, touch, and emotional feeling with "meaning"-but "ultimate significance"-the deepest meaning at which one arrives by dint of mystical effort. Yet if, as Geertz asserts, the meanings that symbols, the material vehicles of thought, embody are, in principle, capable of being discovered, they are not fundamentally different from the intelligible meaning formulated in the anthropologists' concepts. ${ }^{4}$ Indeed, collective performances have the same function as the anthropological discourse: the Balinese cockfight is for Balinese a sentimental education, Geertz explains (Geertz, 1973: p. 449), a text that articulates for and reflects to the Balinese the emotions with which individuals are put together and society is built, the look, uses, force of, and fascination with the violence in their highly stratified and ceremonious society.

Geertz characterizes symbols as models or templates. Speaking of symbols as models or a templates, he is leaving aside the mental intention by which the thinker takes a perceived pattern as a symbol and instead attends to features of the symbolic object itself: on the model we see in reduced scale the building that exists—a model of it—or in reduced scale the building the architect plans to build—a model for it. The model may well depict the structure of what it is a model of or a model for on a different material medium: a map depicts altitudes on the flat surface of paper; a musical score depicts sounds by visual marks. What about thinking that works only

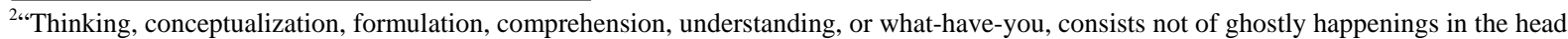
but of a matching of the states and processes of symbolic models against the states and processes of the wider world” (Geertz, 1973: p. 214). 3"Every conscious perception is, a Percy has argued, an act of recognition, a pairing in which an object (or an event, an act, an emotion) is identified by placing it against the background of an appropriate symbol: It is not enough to say that one is conscious of something; one is also conscious of something being something. There is a difference between the apprehension of a gestalt (a chicken perceived the Jastrow effect as well as a human) and the grasping of it under its symbolic vehicle. As I gaze about the room, I am aware of a series of almost effortless acts of matching: seeing an object and knowing what it is” (Percy, 1958: pp. 631-641). Cited in Geertz, 1973: p. 215.

4"Symbols are tangible formulations of notions, abstractions from experience fixed in perceptible forms, concrete embodiments of ideas, attitudes, judgments, longings, or beliefs” (Geertz, 1973: p. 91).
} 
with words that is not uttered outwardly? Here what functions as the symbol, the model or template, would be a neurological pattern in the thinker’s organism or brain (Geertz, 1973: p. 214).

\section{Symbolic Perception}

The term "match" implies that there is nonsymbolic perception, just seeing, hearing, and touching things as they present themselves, and the perceiving, or recalling or imagining, of the model. But it turns out that for Geertz all perception is from the start symbolic. Perception is recognition; we do not simply perceive something, we perceive something being something (Geertz, 1973: p. 215). We do not perceive streams of drifting colors and shapes; we see "chairs" and "buildings"; we hear "melodies" and "alarms". Here the term "match" proves to be misleading. We possess (recall or imagine) the models for "chair" and "alarm" and they function to focus our eyes and hearing that segment the visual or auditory flux into discrete segments with contours and inner structure and tonality. Thus perceiving symbolic objects makes perceiving in general, perceiving things and events, possible.

The models are not innate Platonic ideas or concepts fashioned by our minds; we find them existing in the images, markings, gestures, rituals and ritual objects, tools, and language of the culture. "Meaning is not intrinsic in the objects, acts, processes, and so on, which bear it, but imposed upon them; and the explanation of its properties must therefore be sought in that which does the imposing-men living in society” (Geertz, 1973: p. 405). Thinking, that is, perceiving and manipulating symbols, is not something that goes on within the invisible sphere of the mind; it goes on in the houseyard, the marketplace, and the town square (Geertz, 1973: p. 360). There thinking is grasping vegetables, pieces of wood, tools that are shaped as such for perception by the models.

Everything we perceive is then not only culturally identified but also articulated into objects by cultural symbols. There are no what Bernard Williams (2000: pp. 45-53) called "plain truths; there is no fundamental layer of things, events, and relationships accessible to common sense; common sense is a cultural system differently laid out in different societies (Geertz, 1983: pp. 73-93).

The phenomenology of perception, however, brought to light a "natural world" of sensory and intersensorial figures, gestalts, and ground. And sometimes is not what we see-and what we hear, what we touch, that we smell, what we taste-a field and depth without surfaces, a flux? We are dazzled by throbbing light, we see shifting fog, we hear rumble, we feel the muddy current.

We see the trees, and not the spaces between the trees, as configurations ${ }^{5}$. The lemon that takes form as we focus our eyes closes its contours and detaches from the background; its different sensorial aspects hold together, appearing each in the others (Merleau-Ponty, 2000: pp. 229-230). Its color reveals already the rubbery texture of the rind and the liquid interior and already presents something of its taste: we see that this homogeneous pale yellow of the interior will not taste like brown sugar or shredded wheat. Whatever appears to be real is open to intersensorial exploration.

In a glance around the room, or out the window, we successively see objects set in relief against the background, and the background breaks up into dozens, hundreds, thousands of latent objects, potential figures against the background. We do not see them as things by recognizing what they are, by placing them against the background of appropriate symbols. Many, most of them are nameless, meaningless.

The perceived field about us is in continuous transition, and we perceive things to come in series and sequences. We see a tree among trees, a cloud among clouds, a fellow-human among fellow-humans. In an intellectualist epistemology, this was explained by saying that we abstract, extract, from the flux of appearances, or project into it, the concept of "tree", the set of traits common to the trees, or, in Geertz's terms, the "model". Maurice Merleau-Ponty (1968: pp. 132-133) gave a much more insightful account when he said that we see that trees and clouds, the humans too, are perceived to come in "families". They are perceived as variants of one another. In Ludwig Wittgenstein's example, when we see that Tom, Dina, Harry and Harriet are brothers and sisters we do not see some set of traits, some model, that is the same in each of them. What we see is that the facial structure of Tom resembles that of Dina; the big frame and posture of Dina resembles that of Harry; the gait and gestures of Harry resembles that of Harriet. From one lemon to the next we see variations and also resemblances in shape, in hue, in elasticity, and likewise from lemons to limes and grapefruit. But in fact we do not have a concept of a lemon, a definition that itemizes the traits identical in all particulars.

\footnotetext{
${ }^{5}$ One will point out that in ambiguous perception, we can circumscribe, in a drawing, either a rabbit or a vase. But this does not mean that we project onto amorphous material one model or the other; the drawing has been made in such a way that by focusing on one area or the other a rabbit or a vase arises as the figure against the background.
} 
Because we perceive things, gestalts, and perceive family relationships among them, they could then function as models for other things. A lemon could be taken as a symbol or a model of something else, of perhaps different things in different contexts, in different societies. We see the buildings of the Kasbah as so many cubes, geometrical forms. We see a young couple as Romeo and Juliet or Rama and Sita.

There is also seeing things as they are. Jean-Paul Sartre's Nausea (1969: pp. 127-131) tells of perceiving things stripped of the names, labels, categories we have put on them. Almost any contemplation of an orchid, a moth, a wild turkey, a cloud makes us aware of the forced character of our socially dominant anthropocentric, teleological, and pragmatic/utilitarian frames of reference (Murdoch, 1970: p. 85).

Where recognition in perception does mean "matching" up the perceived gestalt with the model, this does not only effect an articulation of the perceived: a sharper delineation of its contours, an emphasis on its structure or colors or textures that serve as significant traits. But the particularities of the perceived gestalt can then recede from view, to the point that the model conceals the particular. "When I recognize a strange bird as a sparrow, I tend to dispose of the bird under its appropriate formulation: it is only a sparrow" (Percy, 1958: pp. 631-641).

In religious ritual, the ritual objects and the sacred personages being portrayed can cover over the perception of those objects and the humans participating in the ritual so that only the sacred power of the objects and the sacred personages are perceived. The sacred powers are then not represented, but presences (Geertz, 1973: p. 118). Geertz describes religious ritual as producing a kind of generalized gestalt shift such that the participants no longer see the everyday world but the cosmic theatre.

\section{Emotions as Cultural Artifacts}

Geertz affirms that symbols—-models—also articulate, generate and regenerate specific feelings and emotions. Indignation, a feeling of injustice, of frustration of our expectations and plans, envy, jealousy, triumph — words and cultural symbols make them possible. Words and cultural symbols determine what we laugh over and what we grieve over. "Not only ideas, but emotions too, are cultural artifacts in man,” Geertz declares (Geertz, 1973: p. 81).

Geertz depicts ritual, myth, and art—and, he adds, models drawn from popular culture ${ }^{6}$-as templates that segment, articulate, generate and regenerate specific moods, emotions, and attitudes. What is it that they articulate? "Physical sensations" now pleasure, now pain, Geertz says, the "general, diffuse, ongoing flow of bodily sensation.” (Geertz, 1973: p. 80; Hebb, 1946: pp. 88-106; 1949, 1954; Hebb \& Thompson, 1954). "Man cannot perform efficiently in the absence of a fairly high degree of reasonably persistent emotional activation" (Geertz, 1973: p. 80). But this emotional excitability has to be articulated into formed, significant emotions ${ }^{7}$.

In reality the "intrinsic emotional susceptibility" (Geertz, 1973: p. 79) of our organisms is not an amorphous continuum, a diffuse flow of bodily sensation; from the start our affective impulses are as varied in nature, in quality and intensity, as the perceived objects to which they $a_{t t a c h}{ }^{8}$. We perceive things and events that are suggestive, attractive, alluring, appetizing, frightening, threatening, repulsive. The languid movement of the waves of the summer lake attracts us; in the burning heat and wide shifts of the leaping flames we see the fire is dangerous. From infancy our organism responds with very different emotions to things and events we first perceive in massive forms, and our emotions become more strongly articulated and differentiated in the measure that our perception of things and events becomes more finely focused ${ }^{9}$. Adolescents and adults, we walk through the rain forest and may well have only very general words for, and hardly any mythical or artistic models for the successive attraction for, enthrallment with, bliss, repulsion we feel before the immense variety of dark shade, clearings of light, bubbling streams, fetid swamps, whining of mosquitoes, tinkling melodies of birds we perceive.

The brief or sustained emotions that arise during our walk may not have meaning, may not be a model for anything, may close in on themselves. And they can have a felt family resemblance with other emotional impulses.

Emotions focus our perception and what provoked intense emotion is much more strongly impressed upon our

\footnotetext{
6“'In order to make up our minds we must know how we feel about things; and to know how we feel about things we need the public images of sentiment that only ritual, myth, and art can provide” (Geertz, 1973: pp. 82, 216).

${ }^{7}$ Here referring to Susanne (Langer, 1973: p. 372).

${ }^{8}$ In discussing current discourse about ideologies; Geertz says that "there is a good deal of talk about emotions 'finding a symbolic outlet' or 'becoming attached to appropriate symbols'-but very little idea of how the trick is really done” (1973: p. 207). But if, as Geertz says, symbols are matched up with segments of what is only a "general, diffuse, ongoing flow of bodily sensation", the matching is arbitrary and unmotivated, and he too does not show us how the trick is done. In reality they are matched up with emotional impulses that correspond to them and elicit them.

9"Where, we might inquire, does the child gain the capacity, ability, or habit of "reading" cultural bodies in the first place if not in some internal or psychobiological parts of its being?" (Chodorow, 1999: p. 161).
} 
memory. In the succession of our encounters with dogs, the dog that attacked us stands out. It may become the symbol for other vicious animals, for vicious humans, for military assaults ("the dogs of war"). Geertz affirms that symbols articulate, generate and regenerate emotions, but emotions also generate symbols.

"Matching” these already articulated moods and emotions with public images of sentiment from ritual, myth, and art or from popular culture gives us a lexicon with which to talk about our feelings with others, but in addition may function to intensify them. Drifting in a summer lake, the image of tropical paradises, or the overture to Wagner's Rheingold that we play on our Walkman holds our attention on, prolongs, and intensifies our languid pleasure.

But also just as when we recognize a strange bird as a sparrow, we tend to dispose of the bird under its appropriate formulation, giving a name to our emotion, or shaping it according to a model from ritual, myth, art, or popular culture may well conceal it, and weaken it. At the gathering we find ourselves strangely moved by a man we don’t know, furtively glancing back at him. “Oh, he's a realtor,” we are told, and the aura about him simplifies. We tell ourselves "He reminds me of my father," "He looks like Clint Eastwood," and we do sense that we are smudging and pushing down the confused throbbings of awe, fear, eroticism, wariness, anxiety we felt.

\section{Perceiving with Others}

Conceptualizing insight, understanding, conceptual thinking, imagination, feeling, reflection, fantasy as propensities, capacities, tendencies, habits or skills that employ the symbols in a culture as models constitutes what Geertz calls "the extrinsic theory of the mind"10. It makes possible interpretive anthropology as a natural science like any other. It also involves a kind of methodological solipsism. "The ethnographer does not, and, in my opinion, largely cannot, perceive what his informants perceive. What he perceives is what they perceive "with”-or "by means of” or "through” (Geertz, 1983: p. 58) "We can no longer claim some unique form of psychological closeness, a sort of transcultural identification, with our subjects” (Geertz, 1983: p. 58); we do not know what their moods, sentiments, and attitudes through empathy. Attentiveness to others, "ego effacement” (Geertz, 1983: p. 70), and fellow feeling are not the means of anthropological understanding; they are only means to get "people to tolerate our intrusion into their lives at all and accept us as persons worth talking to.” (Geertz, 1983: p. 70).

We do not perceive what our informants, what others perceive? But to see a fellow-human to see the movements of a perceived organism not simply moved by internal spasms or physical impact by physico-chemical entities and electromagnetic events, but responding to the environment that that organism perceives. The environment he or she sees is open to me too. The environment that I see is not a private theater; I see the chairs, trees, and buildings as visible from different points of view themselves visible in that environment, possibly and actually occupied by other sentient organisms. The tree is there and not a momentary phantasm in that it unfolds a continuous aspect as I move toward it and about it. When I see the little pond in the garden of my rented house in Bali it looks like it can be seen from different viewpoints, viewpoints I can go occupy and which others can occupy also. I see that I can go over to the garden gate where my Balinese visitor is standing and see the pond as he sees it from there. Indeed, to see a dog or a bird as alive and sentient is to see that they see the food I put out for them or the stick I throw at them.

Similarly, to see that my visitor is startled and revolted is to see with him the cat leaping upon a screaming bird and to feel startled and revolted also. Kenneth Read (1965: pp. 251-252) without understanding the words of the songs and only the general sense of the all-night ritual in the New Guinea High Valley that brings a young Gahuku-Gama girl to the morning of the day on which she must assume the status of mature woman and be transferred to her husband's village and people, shares the anxiety and solidarity that that young woman and her kinspeople knew.

There is an original experienced equivalence of moods, feelings, and attitudes with stances and movements in the world originally perceived as common to us. Suddenly the window shatters and a dead snake is thrown onto the floor. Before the startling event my eyes open wide and my stance holds back and stiffens. I see that my dog is startled too. To contrive doubt about that would require to construct (and verify) an argument that my emotion is a purely psychic event that has but one witness, and that I can see my dog only as a colored shape moved by the impact of physico-chemical and electromagnetic stimuli.

\footnotetext{
${ }^{10}$ Geertz, 1973: p. 214. Taking up the term from Galanter \& Gerstenhaber, 1956, pp. 218-227.
} 


\section{Understanding the Meaning, the Use, of Symbols}

"Culture is best seen not as complexes of concrete behavior patterns-customs, usages, traditions, habit clusters-as has, by and large, been the case up to now, but," Geertz writes, "as a set of control mechanisms—plans, recipes, rules, instructions (what computer engineers call “programs”)—for the governing of behavior.” (1973: p. 44) —Shouldn't we also say: for the consecration, exaltation, transfiguration of individual and collective life?

The anthropological research is not simply an inspection of the symbolic objects in a culture; it requires a study of their use in patterns of behavior ${ }^{11}$. These are also external and empirically observable.

But what is it to use an image, marking, gesture, ritual, ritual object—or a word—significantly? To understand that the words someone issues are an assertion, a question, a rebuke, or a sarcasm we have to understand not only the grammatical context in which they appear, but also the setting and the circumstances as the speaker views certain of their features and latent possibilities with specific angles of interest and feeling.

We learn and teach words in certain contexts, and then [philosopher Stanley Cavell explains] we are expected, and expect others, to be able to project them into further contexts. Nothing insures that that projection will take place (in particular, not the grasping of universals nor the grasping of books of rules), just as nothing insures that we will make, and understand, the same projections. That on the whole we do is a matter of our sharing routes of interest and feeling, modes of response, senses of humor and of significance and of fulfillment, of what is outrageous, of what is similar to what else, what a rebuke, what forgiveness, of when an utterance is an assertion, when an appeal, when an explanation—all the whirl of organism Wittgenstein calls "forms of life”(Cavell, 1969: p. 52).

The utterances of people we hear are performative acts: they do not just have a grammatical organization that diagrams or models something; they order us, appeal to us, put demands on us, judge, praise, condemn, persuade, ingratiate, coax, wheedle, tease, bore us. When someone turns to us, faces us, speaks, he or she requires a response. With everything we say to him or her, we see how we affect him, trouble her, question, distress, probe, anger, support, amuse, console him or her ${ }^{12}$. Watching a nonverbal performance, a policeman stepping across the floor the dance club, a lineman climbing a pole to repair high-tension wires broken by an ice storm, produces effects in us - provoke performances, verbal, attitudinal, emotional, from us.

Feeling awe in the cathedral during solemn high mass, the child understands reverence. The child who happens upon a couple making love sees it as aggression until the feelings and gestures of eroticism arise in him or her (Merleau-Ponty, 2000: p. 84). Observing the uses of, interpreting the images, markings, gestures, rituals, ritual objects of another culture does require sharing interest and feeling and modes of response.

\section{Private Myths}

"Human thought is consummately social: social in its origins, social in its functions, social in its forms, social in its applications” (Geertz, 1973: p. 360). The images, markings, gestures, rituals and ritual objects, tools, and words are made by groups of people, or, if made by individuals, made in view of others and while communicating with others.

What happens if another cultural complex with its symbolic system were to encroach upon a culture? There arise elders or visionaries who have to make sense of the overlapping of two divergent symbolic systems in order to map out how people are to make sense of their situation and live their lives now. This is the work of marginal leaders-medicine men, faith healers, Voodoo serviteurs and Candomblé priestesses, "Cargo Cult” Messiahs. They do not like theologians work to integrate into a logically coherent system the two conflicting mythologies; their interventions and inventions are ad hoc, they work by bricolage.

Something of this situation holds for an individual even in a culture and community not being disrupted and encroached upon from without. The individual finds himself in a natural and social environment where there are symbolic systems to make sense of, to model physical, organic, social, psychological systems and to provide models for behavior, a set of control mechanisms-plans, recipes, rules, instructions "programs”-for the go-

\footnotetext{
11،Behavior must be attended to, and with some exactness, because it is through the flow of behavior-or, more precisely, social action-that cultural forms find articulation. They find it as well, of course, in various sorts of artifacts, and various states of consciousness; but these draw their meaning from the role they play (Wittgenstein would say their "use") in an ongoing pattern of life, not from any intrinsic relationships they bear to one another” (Geertz, 1973: p. 17).

${ }^{12}$ Interpretative anthropology does not only report on, describe, performances, translated into the language its nonacademic and academic readers. Its interpretation is also assessment. Its texts produce effects on their readers, who respond to them with verbal and nonverbal performances.
} 
verning of behavior. But these symbolic systems do not form a grid covering over the whole of the individual's environment. There is much that does not make sense, that like roses are there without having meaning; there is much that arouses moods, emotions, attitudes that close in on themselves and intensify—serenity, exhilaration, composure but also anxiety, cruelty, and pain that break with the past and obturate the future. There is also the fact that the words, the symbols, the models are general while the individual is psychophysical composite such as has not really ever existed before and will never recur, perceiving and acting in a concrete natural and social situation that is individual. Between the grid of general models and his concrete situation there is a gap. The gap becomes, Slavoj Zizek and the Freudians term it, his fantasy space. To make sense of his own individual situation and to live in the intensity of his own vulnerability, susceptibility, sensibility, emotions he will have to fill in the gap with symbols of his own devising — his private myth, Jacques Lacan, following Claude Lévi-Strauss, called it.

Geertz searches out and itemizes the personal names, birth-order names, kinship terms, teknonyms, status titles, and public titles with which individuals are characterized in Bali. Such a set of categories functions in a community to identify an individual, they also function practically, to designate the ways to interact with him or her. And they function for Geertz (1983: p. 58) to characterize what that individual understands by, experiences, and lives out as his "person". Balinese "stylize all aspects of personal expression to the point where anything idiosyncratic, anything characteristic of the individual merely because he is who he is physically, psychologically, or biographically, is muted in favor of his assigned place in the continuing pageant that is Balinese life;" (Geertz, 1983: p. 62) they exist as personages in a drama, their physical reality comes and goes of no genuine importance even to themselves. (Geertz, 1983: p. 62) Geertz concedes (Geertz, 1973: p. 406) that patterns counteractive to this are also found among the Balinese; he cites their experiences of witches and their experiences in trance. These are not individual impulses and drives breaking through the culturally formed personality; they are themselves articulated, generated and regenerated, by cultural symbols (Geertz, 1983: p. 62). But, Geertz does note, this attempt to block out individuality, spontaneity, perishability, emotionality, vulnerability is only partially successful. Who he is physically, psychologically, or biographically does break out and is seen by others. Hence those moments of tension, lek, which Geertz (1983: p. 64) following Corruvubias, Bateson and Mead, calls "stage fright".

Geertz also acknowledges that in Bali the distinction between the public and private is exceptionally sharp. "The boundary between the public and private domains of life is very clearly drawn both conceptually and institutionally. At every level, from the hamlet to the royal palace, matters of general concern are sharply distinguished and carefully insulated from matters of individual or familial concern, rather than being allowed to interpenetrate as they do in so many other societies” (Geertz, 1973: p. 385).

For us too the categories by which we are designated in our language and culture do not comprise what each of us understands by, experiences, and lives out as his "person". The common language of physical dynamics and electromagnetism, and of physiology, neurology, psychology, and pragmatic reason-the meaning-system of our culture - has to be applied to our own environment and our own bodies in order to enable us to make sense of how our bodies function or do not function in the situations in which we find ourselves. In seeking to do so, we may find the symbolic system has internal flaws, or else that it does not adequately fit our own environment. Moreover, the meaning system and the categories, are general, while we are individuals in particular situations. There is a gap; each one has to fill in, with meaningful terms, this gap. There we are medicine men, faith healers, Voodoo serviteurs and Candomblé priestesses, occupied with ourselves ${ }^{13}$.

We all know-teachers know, policemen know, marriage counselors, psychotherapists know, spouses and friends know- that to understand one another it is not enough to search out and analyze the personal names, birth-order names, kinship terms, teknonyms, status titles, and public titles with which individuals are recognized in our culture; it is also necessary to seek out the medicine men, faith healers, Voodoo serviteurs and Candomblé priestesses in the individual. We have to envisage the layout of our common natural and social environment as she has staked it out, catch on to the symbols she uses and how they are used and they link up with

\footnotetext{
${ }^{13}$ In 2000 Geertz concedes that "The strongest, most developed challenges to culturalist, symbolic-action theories of emotion, feeling, and passion...come in the form of accusations of a more fundamental, more deeply crippling, even fatal deficiency: their supposed neglect of 'intra-psychic' dynamics and thus their, also supposed, inattention to, and inability to deal with, agency, individuality, and personal subjectivity" (Geertz, 2000: p. 210). These theories, psychoanalyst Nancy Chodorow writes, "are unable to conceive theoretically, even as they describe ethnographically, individual psychological processes of personal meaning creation.... [They] bypass the idiosyncratic, divergent ways in which emotions develop and are experienced.... Where, we might inquire, does the child gain the capacity, ability, or habit of 'reading' cultural bodies in the first place if not in some internal or psychobiological parts of its being?” (Chodorow, 1999: p. 161).
} 
one another. Some of the words and symbols elaborated there become significant for others, are patched in gaps in their own fantasy space, become public symbols. We have to envisage all that does not make sense in his environment, all that confounds and mocks understanding, all that is spirals of pleasure, thrill, rush, speed, agony.

Out of the "private myth" each of us elaborates in his "fantasy space", we may enter into conflict with the meaning system of our culture. Such conflict is not just a feature of modern liberal societies. Since the romantics, anthropologists had focused on the function of myths and rituals to consolidate and strengthen a community and its hierarchies. But the myths and rituals also engender heretics, break-off sects, eccentrics, scoffers, charlatans, and profiteers. Anthropologists competent in psychoanalysis sought to show how myths and ritual function to satisfy the individual's cognitive and affective demands for a stable, comprehensible, and coercible world. But the cultural symbols, models, and paradigms that present to individuals a stable, comprehensible, and coercible society and world also engender internal conflicts in individuals and conflicts with those about them. They clash with the temperament, compulsions, and ambitions of individuals, or they exclude individuals with certain bodies or heredity from a life integrated in itself and integrated into the community ${ }^{14}$.

\section{Conclusion: Limits of the Extrinsic Theory of Mind}

An extrinsic theory of mind takes insight, understanding, conceptual thinking, imagination, feeling, reflection, fantasy as skills, propensities, capacities, tendencies, or habits, which are known by the verbal reasonings, images, and symbols that are observably produced. Yet reasonings can be reproduced without insight, and produced by a simple calculus upon logico-mathematically symbolized formulas. The external expression of emotions can be produced without the emotions.

Geertz takes all perception to be symbolic; things are identified by being from the start matched up with templates. The phenomenology of perception, however, has established that perceiving Gestalten and background are recognizing or identifying things are separate and separable.

Geertz affirms that emotions are cultural artifacts in humans. Without the templates provided by ritual, myth, art, and models drawn from popular culture there is only a general, diffuse, ongoing flow of bodily sensation. But from the start our emotions, identified by us or not, are as varied in nature, in quality and intensity, as the perceived objects they attach to. Anxiety, gloom, depression, and euphoria can arise without being provoked by culturally identified objects.

Geertz affirms that the ethnographer does not, and largely cannot, perceive what his informants perceive. But the phenomenology of perception has established that what an individual perceives is perceived as perceivable from other viewpoints, and by others. The individual enters the building she sees that others also see and enter, and sees the book Geertz sees and hands to her.

To understand the symbolic meaning of a word or cultural object, simple external observation of its use is inadequate; it is necessary to share with the one who uses that word or cultural object a "form of life"-interests, patterns of feeling, and of response, a sense of what is important and what is disproportionate, etc. ${ }^{15}$

The meanings that individuals find and impose of their emotions, desires and practical intentions, as well as on the objects they handle and the events that occur to them are not only those of the externally observable models and templates of their language and culture. Each individual also elaborates what Jacques Lacan and Slavoj Zizek called a "private myth".

\section{References}

Biersack, A. (1989). Local Knowledge, Local History: Geertz and Beyond. In L. Hunt (Ed.), The New Cultural History. Berkeley and Los Angeles: University of California Press.

Boas, F. (1974). A Franz Boas Reader: The Shaping of American Anthropology, 1883-1911. Chicago, IL: University of Chicago Press.

Borofsky, R. (1993). Assessing Cultural Anthropology. Columbus, IO: McGraw-Hill College.

Carrithers, M. (1988). The Anthropologist as Author: Geertz’s “Works and Lives”. Anthropology Today, 4, 19-22.

\footnotetext{
${ }^{14}$ In a culture that declares, in words and in rituals, that death is transition to blessed life, or reincarnation, or heroic glory that will live on in the community, the Christian and the Hindu and the patriotic family weep disconsolately over the death of a child or young son.

${ }^{15}$ In a late review of Cai Hua, A Society without Fathers or Husbands: the Na of China (Brooklyn, NY: Zone, 2001), Geertz complains "There is nothing, or almost nothing of individual feelings and personal judgments, of hopes, fears, dissents, and resistances, of fantasy, remorse, pride, humor, loss, or disappointment 'Na-ness' as a form-of-life, a way-of-being-in the-world, is, whatever it is, a much wider, more ragged, unsettled, less articulated, and less articulable thing.” (2001: p. 29).
} 
http://dx.doi.org/10.2307/3032993

Carrithers, M. et al. (1990). Is Anthropology Art or Science? Current Anthropology, 31, 263-281. http://dx.doi.org/10.1086/203840

Cavell, S. (1969). Must We Mean What We Say? New York: Scribner's.

Chodorow, N. (1999). The Power of Feelings, Personal Meaning in Psychoanalysis, Gender, and Culture. New Haven, CT: Yale U Press.

Clifford, J., \& Marcus, G. (1986). Writing Culture: The Poetics and Politics of Ethnography. Berkeley and Los Angeles: University of California Press.

Crapanzano, V. (2003). Imaginative Horizons: An Essay in Literary-Philosophical Anthropology. Chicago, IL: University of Chicago Press. http://dx.doi.org/10.7208/chicago/9780226118758.001.0001

Descombes, V. (2002). A Confusion of Tongues. Anthropological Theory, 2, 433-446. http://dx.doi.org/10.1177/14634996020020041101

Fabian, J. (1991). Time and the Work of Anthropology: Critical Essays. London: Routledge.

Fettes, M. (2000). (Un)Writing the Margins: Steps towards an Ecology of Language. In R. Philipson (Ed.), Rights to Language: Equity, Power, and Education. New York: Lawrence Earlbaum.

Galanter, E., \& Gerstenhaber, M. (1956). On Thought: The Extrinsic Theory. Psychological Review, 63, $218-227$. http://dx.doi.org/10.1037/h0048568

Geertz, C. (1973). The Interpretation of Culture. New York: Basic Books.

Geertz, C. (1983). Local Knowledge. New York: Basic Books.

(1988). Works and Lives: The Anthropologist as Author. Palo Alto, CA: Stanford University Press.

(1995). After the Fact: Two Countries, Four Decades, One Anthropologist. Cambridge, MA: Harvard University Press.

Geertz, C. (2000). Available Light. Princeton, NJ: Princeton University Press.

Micheelsen, A. (2002). “I Don’t Do Systems”: An Interview with Clifford Geertz. Method \& Theory in the Study of Religion, 14, 2-20. http://dx.doi.org/10.1163/157006802760198730

Geertz, C. (2002). An Inconstant Profession: The Anthropological Life in Interesting Times. Annual Review of Anthropology, 31, 1-19. http://dx.doi.org/10.1146/annurev.anthro.31.040402.085449

Gottowik, V. (1997). Who’s Afraid of “Teutonic Professors”? Anthropology Today, 13, 3-4. http://dx.doi.org/10.2307/2783418

Handler, R. (1991). An Interview with Clifford Geertz. Current Anthropology, 32, 603-613. http://dx.doi.org/10.1086/204008

Hebb, D. O. (1946). Emotions in Man and Animal: An Analysis of the Intuitive Process of Recognition. Psychological Review, 53, 88-106. http://dx.doi.org/10.1037/h0063033

Hebb, D. O. (1949). The Organization of Behavior: A Neurological Theory. New York: Wiley.

Hebb, D. O. (1954). The Problem of Consciousness and Introspection. In J. F. Delafresnaye (Ed.), Brain Mechanisms and Consciousness. Oxford: Blackwell.

Hebb, D. O., \& Thompson, W. R. (1954). The Social Significance of Animal Studies. In D. T. Gilbert, \& G. Lindzay (Eds.), Handbook of Social Psychology (Vol. 1). Hoboken, NJ: Wiley.

Hobart, M. (1990). Who Do You Think You Are? The Authorized Balinese. In R. Fardon (Ed.), Localizing Strategies: Regional Traditions of Ethnographic Writing (pp. 303-338). Edinburgh: Scottish Academic Press.

Hymes, D., Ed. (1999). Reinventing Anthropology. Ann Arbor: University of Michigan Press.

Kapferer, B. (1988). The Anthropologist as Hero: Three Exponents of Post-Modern Anthropology. Critique of Anthropology, 8, 77-104. http://dx.doi.org/10.1177/0308275X8800800206

Kuper, A. (1999). Culture: The Anthropologists' Account. Cambridge: Harvard University Press.

Langer, S. (1953). Feeling and Form. New York: Scribner's.

Lévi-Strauss, C. (1983) Structural Anthropology. Translated by C. Jacobson \& B. G. Schoepf, Chicago: University of Chicago Press.

Malinowski, B. (2001). Scientific Theory of Culture and Other Essays, Vol. 9. Selected Works by Bronislaw Malinowski. London: Routledge.

Marcus, G. (1998). Ethnography through Thick and Thin. Princeton: Princeton University Press.

Merleau-Ponty, M. (1968). The Visible and the Invisible. Translated by A. Lingis. Evanston, IL: Northwestern University Press. 
Merleau-Ponty, M. (2000). Phenomenology of Perception. Translated by C. Smith. London: Routledge \& Kegan Paul.

Milroy, L. \& Gordon, M. (2003) Sociolinguistics: Method and Interpretation. London: Blackwell. http://dx.doi.org/10.1002/9780470758359

Murdoch, I. (1970). The Sovereignty of Good. London: Routledge and Kegan Paul.

Nikityuk, B. A. (1978). Anthropology as a Natural Science. Journal of Human Evolution, 7, 475-488. http://dx.doi.org/10.1016/S0047-2484(78)80015-3

Percy, W. (1958). Symbol, Consciousness and Intersubjectivity. Journal of Philosophy, 55, 631-641. http://dx.doi.org/10.2307/2022067

Radcliffe-Brown, A. R. (1957). A Natural Science of Society. New York: Free Press.

Read, K. (1965). The High Valley. New York: Scribner's.

Rosaldo, R. (1993). Culture and Truth: The Remaking of Social Analysis. Boston: Beacon.

Ryle, G. (1971). Collected Papers, Volume II, Collected Essays 1929-1968. London: Hutchison.

Ryle, G. (1949). Concept of the Mind. London: Hutchinson.

Sartre, J.-P. (1969). Nausea. Translated by L. Alexander. New York: New Directions.

Scholte, B. (1986). The Charmed Circle of Geertz's Hermeneutics: A Neo-Marxist Critique. Critique of Anthropology, 6, 515. http://dx.doi.org/10.1177/0308275X8600600102

Shankman, P. (1984). The Thick and the Thin: On the Interpretive Theoretical Program of Clifford Geertz. Current Anthropology, 25, 261-280. http://dx.doi.org/10.1086/203135

Sherrington, C. (1953). Man on His Nature (2nd ed.). Cambridge: Cambridge University Press.

Tambiah, S. J. (1985). Culture, Thought, and Social Action. Cambridge: Harvard University Press.

Tyler, S. (1987). The Unspeakable: Discourse, Dialogue, and Rhetoric in the Postmodern World. Madison: University of Wisconsin Press.

Tylor, E. B. (1881). Anthropology. New York: Appleton.

Weber, M. (1963). The Sociology of Religion. Boston: Beacon.

Williams, B. (2002). Truth and Truthfulness. Princeton: Princeton University Press.

Yoshida, K. (2007). Defending Scientific Study of the Social against Clifford Geertz (and His Critics). Philosophy of the Social Sciences, 37, 289-314. 